\title{
Correcting Airborne Laser Scanning Intensity Data
}

\author{
Ants Vain ${ }^{1}$ and Sanna Kaasalainen ${ }^{2}$ \\ ${ }^{1}$ Estonian University of Life Sciences \\ ${ }^{2}$ Finnish Geodetic Institute \\ ${ }^{1}$ Estonia \\ 2Finland
}

\section{Introduction}

Airborne laser scanners (ALS) produce a point cloud where each point has $\mathrm{X}, \mathrm{Y}$ and Z coordinates which are determined by the combination of GNSS (Global Navigation Satellite System), IMU (Inertial Measurement Unit) and laser range finder. Additionally to coordinates points have also an intensity value recoded. Intensity values are recorded in digital numbers and represent the number of photons that are impinging the detector (Coren \& Sterzai, 2006). Intensity values are related to the energy coming back to the receiver. Since the ALS systems operate on the same physical basis as radar we can use the radar equation (Wagner, 2010):

$$
P_{r}=\frac{P_{t} D_{r}^{2}}{4 \pi R^{4} \beta_{t}^{2}} \eta_{\text {sys }} \eta_{\text {atm }} \sigma
$$

where $P_{r}$ is the power that has been received, $P_{t}$ is the power that was transmitted, $D_{r}$ is the receiver aperture diameter, $R$ is the range from sensor to the object, $\beta_{t}$ is the laser beam width, $\eta_{\text {sys }}$ is the systems transmission factor, $\eta_{\text {atm }}$ is the atmospheric transmission factor and $\sigma$ is the cross-section of the target. As we can see from equation (1) the intensity (or received power) is connected to the power that has been transmitted, the range from sensor to the object, how the beam is diverged, system and atmospheric transmission and the footprint size of the laser beam.

The cross-section $\sigma$ can be described with a following equation (Höfle \& Pfeifer, 2007):

$$
\sigma=\frac{4 \pi}{\Omega} \rho A_{s}
$$

where $\Omega$ is the scattering solid angle of the target, $\rho$ is the reflectance of the target and $A_{s}$ the area illuminated by the laser beam. $\mathrm{A}_{\mathrm{s}}$ can be written as a function of distance $\mathrm{R}$ and beam width $\beta$ (Höfle \& Pfeifer, 2007):

$$
A_{s}=\frac{\pi R^{2} \beta_{t}^{2}}{4}
$$


When we substitute $A_{s}$ in equation (3) to equation (2), we get:

$$
\sigma=\pi \rho R^{2} \beta_{t}^{2} \cos \alpha
$$

Substituting this into equation (1) we get a new radar equation:

$$
P_{r}=\frac{P_{t} D_{r}^{2} \rho}{4 R^{2}} \eta_{s y s} \eta_{a t m} \cos \alpha
$$

The $\eta_{\text {sys }}$ is the optical transmission efficiency for all optical components of ALS system (Höfle \& Pfeifer, 2007). It is a constant for a certain ALS system but it may vary with different sensors. The $D_{r}$ component is also a constant when using one type of sensor. The $a$ is an incidence angle, which is defined as an angle between incoming laser beam and surface normal.

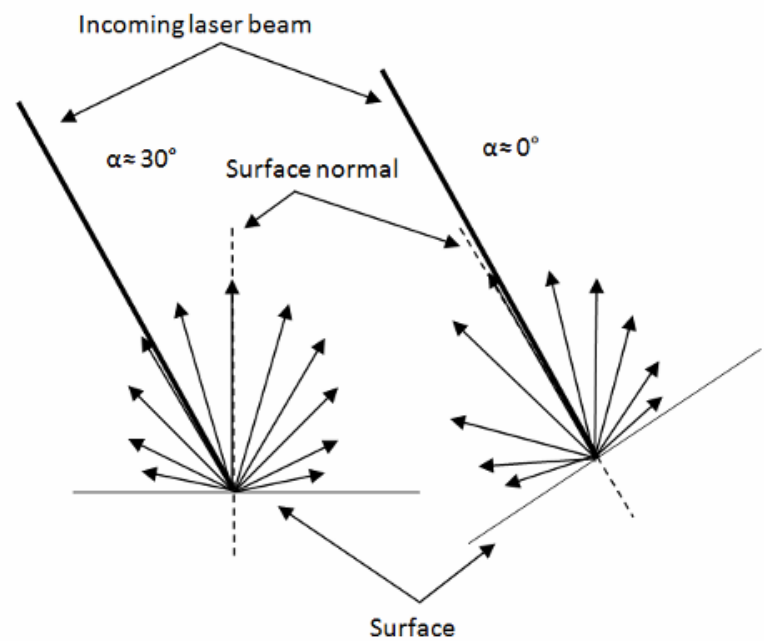

Fig. 1. Lambertian scattering of the surface. Topographic effect on incidence angle.

As we can see from Fig. 1 the cosa part in equation (5) depends on the surface roughness. When the measured area is flat then the incidence angle is the same as scan angle. The surfaces are assumed to have Lambertian backscattering properties. This means that the energy that is backscattered from the surfaces decreases with the increase of incidence angle. It is clear that those factors have to be taken into account when we want to use the intensity data.

\section{Factors affecting the intensity}

\subsection{Atmospheric correction}

When we are using ALS data it is clear that the atmospheric conditions are affecting the intensity values. Since most of the ALS systems use $1064 \mathrm{~nm}$ wavelength it is important to notice that scattering effect is much larger than absorbtion in that particular wavelength (Kim et al., 2001). It is also reported that the attenuation of horizontal propagation can be from $0.2 \mathrm{~dB} / \mathrm{km}$ for very clear weather conditions to $3.9 \mathrm{~dB} / \mathrm{km}$ for haze conditions (Höfle 
\& Pfeifer, 2007). If we look at the vertical path of laser beam then the atmospheric transmittance increases with higher altitudes (Höfle \& Pfeifer, 2007). From the Beer-Lambert law the intensity I can be written as:

$$
I=I_{0} e^{-\alpha x}
$$

where $\mathrm{I}_{0}$ is the incident intensity, $a$ is the atmospheric attenuation in $\mathrm{dB} / \mathrm{km}$ and $x$ is the path length (from the sensor to the object). The part $\mathrm{e}^{-a x}$ in the equation (6) is also called atmospheric transmittance $(\mathrm{T})$. Knowing that we can write for equation (5) the $\eta_{\text {atm }}$ as a function of atmospheric transmittance $\mathrm{T}$ :

$$
\eta_{a t m}=\frac{1}{T^{2}}
$$

$\mathrm{T}$ describes the properties of atmosphere and can vary from 0 to 1 ( 1 referring to clear transmittance of atmosphere). The value of $\mathrm{T}$ depends on the weather conditions (e.g. visibility, air temperature, humidity, aerosol concentration) but also on the flying altitude. Most of the flight are made in clear weather but usually after the rain. This means that the humidity might be high. Since the lack of information about the weather conditions during the flights, we have to use programmes that calculate approximate values for T. The usual inputs for these programmes are: wavelenght, visibility, atmospheric model, path length, environment (rural or urban).

\subsection{Range correction}

When we look at the equation (5) we can notice that the recieved power (or intensity) has an inverse range square dependency $\left(1 / R^{2}\right)$. The $1 / R^{2}$ dependency applies to the extended diffuse targets. This means that the entire footprint is reflected on one surface and it has Lambertian scattering characteristics (see Fig. 1). This is not always the case. Targets that are smaller than the laser footprint size (e.g. a small tree branch or a leaf) are range independent non-extended diffuse targets. And targets that have linear physical properties (e.g. wire) are linear range dependent (Höfle \& Pfeifer, 2007). For a target smaller than laser footprint size the range dependency becomes $1 / \mathrm{R}^{4}$, and for linear targets $1 / \mathrm{R}^{3}$. In practical applications, it is very hard to determine weather the target was smaller than a footprint size or not.

To correct the intensity values for range dependency a reference altitude should be chosen. For this purpose we have to know the distance from sensor to the object for every individual laser point. Also, incdence angle correction should be applied. But in some cases it is hard to determine the incidence angle, e.g. for trees. Incidence angle correction can be left out if the scan angle does not exceed 20 degrees on the flat surface, because the error caused by the incidence angle is smaller than errors in measuremnts. Intensity values start to decrease significantly from 20 degrees (Kukko et al., 2008). The range correction or sometimes also called sperical loss can be written (Vain et al., 2009):

$$
I_{\text {Rcorr }}=I_{o b s} \frac{R_{i}^{2}}{R_{r e f}^{2}}
$$

where corrected intensity for sherical loss ( $\left.\mathrm{I}_{\mathrm{Rcorr}}\right)$ is a function of observed intensity $\left(\mathrm{I}_{\mathrm{obs}}\right)$, Ri (the slope distance from sensor to the object) and $R_{\text {ref }}$ (the chosen reference distance). For 
example, if the flying altitude is around $500 \mathrm{~m}$ then the slope distance with 20 degree scan angle will be around $530 \mathrm{~m}$. Then it is proper to choose $500 \mathrm{~m}$ as reference distance $\left(\mathrm{R}_{\text {ref }}\right)$.

\subsection{Pulse energy correction}

One of the critical parts in correcting ALS intensity data is the pulse energy correction. It is problematic because the transmitted pulse energy is usually unknown. There is an improvement with the newer pulse ALS systems and some pulse scanners can even record wavefroms of detected signal as well. Since the intensity data is strongly connected to the transmitted pulse energy level (see equation (5)) it has to be taken into consideration when using data from different flights that have different pulse energy settings. The average power $\left(\mathrm{P}_{\mathrm{av}}\right)$ that is transmitted is a function of pulse energy and pulse rate (also called pulse repetition frequency, PRF) (Baltsavias, 1999):

$$
P_{a v}=E F=P_{\text {peak }} t_{p} F
$$

The $t_{p}$ is the pulse duration that is usualy couple of nanoseconds. Pulses with shorter duration time can carry more energy but are less stable than pulses with longer duration time. The $P_{\text {peak }}$ is the peak power of the transmitted laser pulse. The pulse energy $E$ is connected to the $t_{p}$ and $P_{\text {peak }}$ so that the energy level will decrease with the decrease of peak power $P_{\text {peak. }}$ Peak powers for Optech scanners are reported by Chasmer et al., (2006). With the higher PRF setting the transmitted energy is lower (Chasmer et al., 2006; Baltsavias, 1999), which reduces the penetration rate of the laser pulse. This means less points under the canopy and also almost double error in height component when using $50 \mathrm{kHz}$ or $100 \mathrm{kHz}$ settings (Chasmer et al., 2006). Even though the higher PRF settings will give more points, they might not reach to the ground. The PRF settings should be selected according to the vegetation density and application purposes. For correcting intensity data for different energy levels, a simple formula is used (Vain et al., 2009):

$$
I_{\text {Ecorr }}=I_{o b s} \frac{E_{T r e f}}{E_{T j}}
$$

The corrected intensity ( $\left.\mathrm{I}_{\mathrm{Ecorr}}\right)$ is a function of observed intensity $\left(\mathrm{I}_{\mathrm{obs}}\right)$, chosen transmitted reference pulse energy value $\left(\mathrm{E}_{\mathrm{Tref}}\right)$, and the transmitted pulse energy value in current flight $\left(\mathrm{E}_{\mathrm{T}}\right)$. The $\mathrm{E}_{\text {Tref }}$ is an energy value in one of the flights that are used, e.g. when you are comapring two flights with different PRF setting and you know the transmitted energy values, you choose one of the energy levels as reference.

\subsection{Intensity correction formula}

Summarizing the previous, we can write the correction formula as follows (Vain et al., 2009):

$$
I_{\text {corrected }}=I_{\text {original }} \frac{R_{i}^{2}}{R_{r e f}^{2}} \frac{1}{\cos \alpha} \frac{1}{T^{2}} \frac{E_{\text {Tref }}}{E_{T j}}
$$

To correct the intensity values we need to know several parameters. First, the atmospheric conditions during the flight campaign. Since the atmospheric conditions play quite important role in laser beam attenuation, weather conditions have to be taken into account as much as possible using atmospheric modelling programmes. The second important part 
is energy losses during the travelling time of laser pulse. The effect of different pulse properties might be large enough to be confused with temporal variation in vegetation structure (Chasmer et al., 2006). If the scan angle exceeds the 20 degee limit, it starts to affect the intensity values quite much (Kukko et al., 2008). But the correction proceedures so far are using incidence angle correction for flat surfaces only, because it is hard to determine the incidence angle for trees or other vegetation. For this reason, Wagner (2010) proposes the use of backscattering coefficient to be used as a calibration parameter for laser scanner intensity. The range differences has an effect on intensity data also. Therefore it has to be corrected using range squared dependency for large areas.

\section{Calibrating the intensity data}

\subsection{Commercial tarps}

When we want to compare the intensity data for the same area, but we have used different sensor types and settings, some kind of reference target is needed to unify the data sets. Brightness targets (see Fig. 2) have proven to be suitable for calibration purposes.

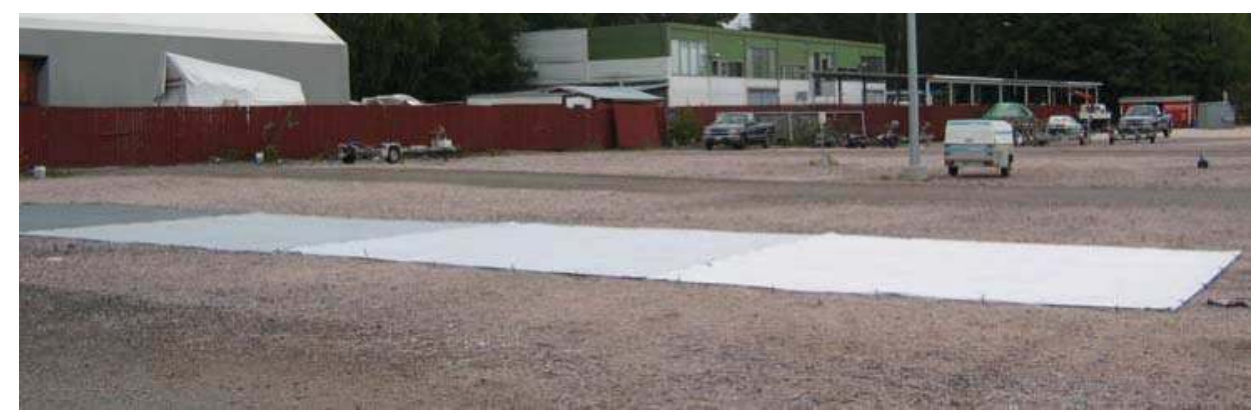

Fig. 2. Brightness targets placed on the ground during the campaign in August 2006, Espoonlahti, Finland.

These brightness targets (tarps) are made of polyester 1100 dtex with polyvinyl chloride (pvc) coating. The weight of that fabric is $600 \mathrm{~g} / \mathrm{m}^{2}$ and they are coated with titanium dioxide and carbon black paint mixing pigment. To decrease the non-Lambertian reflectance effect a delustring agent was added to the paint which gives a mat surface. However, the mat surface is quite sensitive to the dirt, which means that the tarps have to be cleaned often. The size of these tarps is $5 \times 5 \mathrm{~m}$, which makes them easy to transport but at the same time large enough to get reasonable number of laser points.

The tarps were measured at the Finnish Geodetic Institute (FGI) laboratory. For ALS application a $1064 \mathrm{~nm}$ laser (diode-pumped $\mathrm{Nd}: \mathrm{YAG}$ ) was used with the polarization ratio of 100:1. $1064 \mathrm{~nm}$ wavelength is usual for most of the ALS scanners. A basic laboratory measurement setup is shown on Fig. 3.

For the calibration purposes in the laser laboratory a 99\% Spectralon (Labsphere, Inc.) plate was used. The tarps had nominal reflectances of $5 \% ; 10 \% ; 20 \% ; 25 \% ; 30 \% ; 45 \% ; 50 \%$ and $70 \%$. Detailed information about the tarps is given in Kaasalainen et al., (2005) and Kaasalainen et al., (2008).

These tarps have proved to be good reference targets and have been used also in photogrammetric measurements in several studies (Honkavaara et al., 2008). 


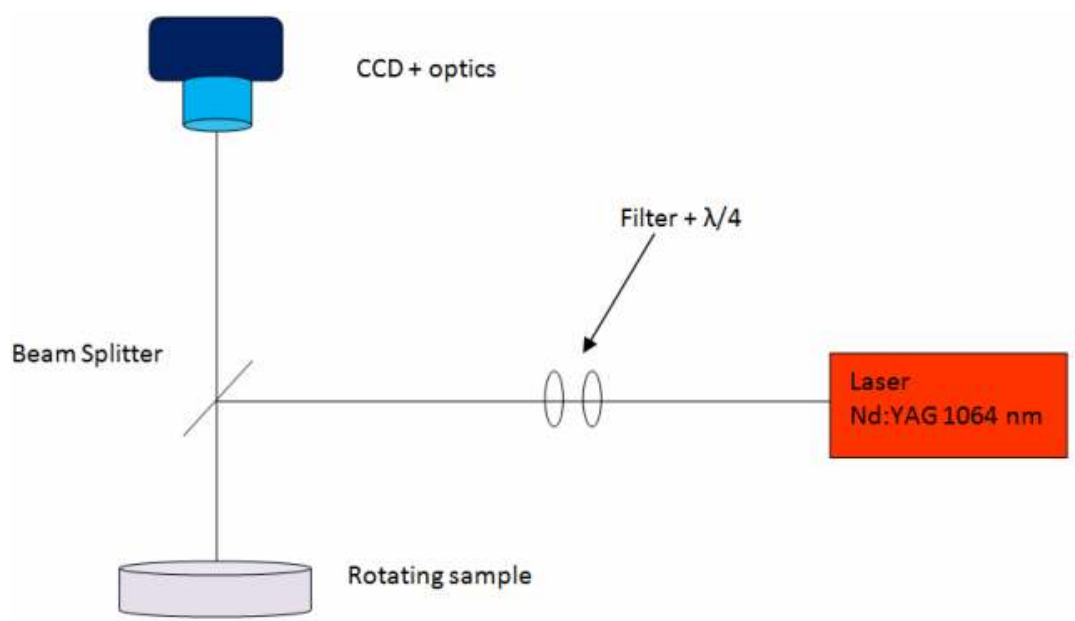

Fig. 3. Setup of the FGI laser laboratory. The sample is placed on a rotating base. CCD camera records the photons that backscatter from the sample. Filter was used to keep the signal in the linear range of the CCD camera. CCD camera is on top of the beamsplitter, 110 $\mathrm{cm}$ from the sample.The distance from the sample to the beam splitter is $15 \mathrm{~cm}$. The quaterwave plate was used to scramble the polarization.

\subsection{Using natural or semi-natural material to calibrate the intensity}

The reference tarps are stable targets to use in calibration process. However, it is not always possible to use them. They have to be placed on the ground before the flight takes place and they must be cleaned once in a while to remove the dust. For this reason a possibility to use natural or semi-natural targets (in this case asphalt and concrete are referenced as seminatural targets) was studied.

To study the stability of natural and semi-natural targets a data set from 2004-2007 for the test area in Espoonlahti, Finland was used. Sensors were Optech, Topeye and Leica with different flying altitudes and parameters. The intensity of the laser points were corrected according to the equation (10), leaving out the pulse difference correction, simply because of the lack of information about it. The samples were also collected and measured in the laser laboratory (see Fig. 3), and a digital camera solution was tested (see Fig. 6). The most promising and stable results were from the asphalt (Coren \& Sterzai, (2006) have also used asphalt to calibrate the intensity data).

Fig. 4 shows that the asphalt is a quite stable calibrator. The differences between sensors are caused by the lack of information about the energy levels used. Also, ALS50-II system uses the AGC (see Ch. 4) and the correction formula for that is not applied in this study.

\subsection{Moisture effect}

One of the factors that affect the intensity values is the moisture level in the target. It is quite common that the airborne measurements are made after the rain. Fig. 5 shows the gravel road in East-Finland where one part of the road was made wet with water during the flight. The results show that the moisture has an effect on intensity data, making it lower than the dry road data. 
Fig. 5 shows that the moisture reduces the intensity level and makes the intensity image "darker". It means that the knowledge about the moisture level in the target is important. For this purposes a camera-based solution was introduced (Vain et al., 2009) with calibration frame. This helps to make in-situ measurements that are more realistic than laboratory measurements, because the conditions are more close to the actual ones. The camera uses NIR spectrum that is quite close to the ALS measurements $(1064 \mathrm{~nm})$. This kind of system helps to study the variations in one type of sample and also study the moisture effect on intensity.

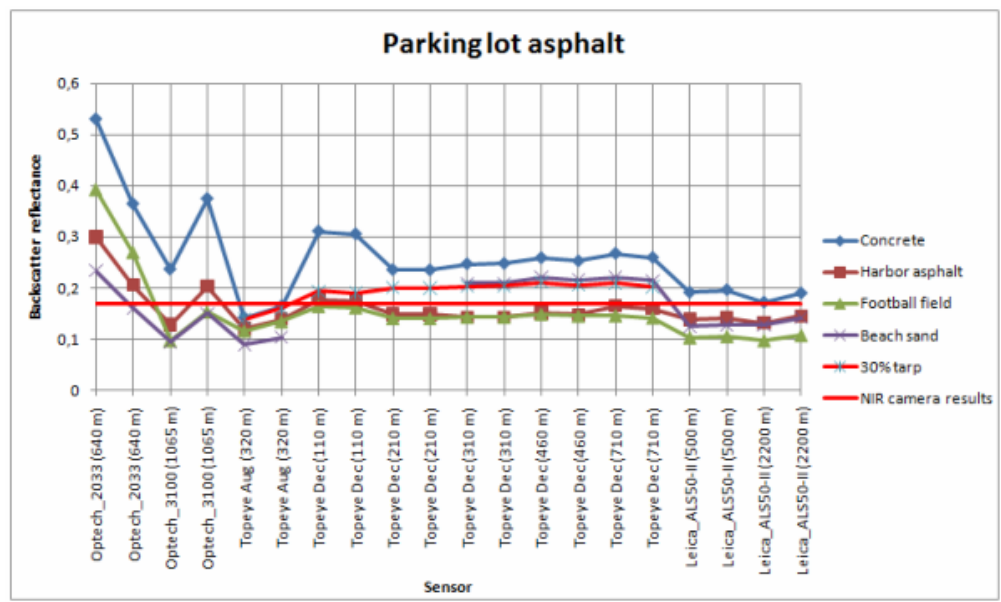

Fig. 4. Results of the parking lot asphalt. Calibrated intensity data from different sensors using parking lot asphalt sample as reference target. (Vain et al., 2009)

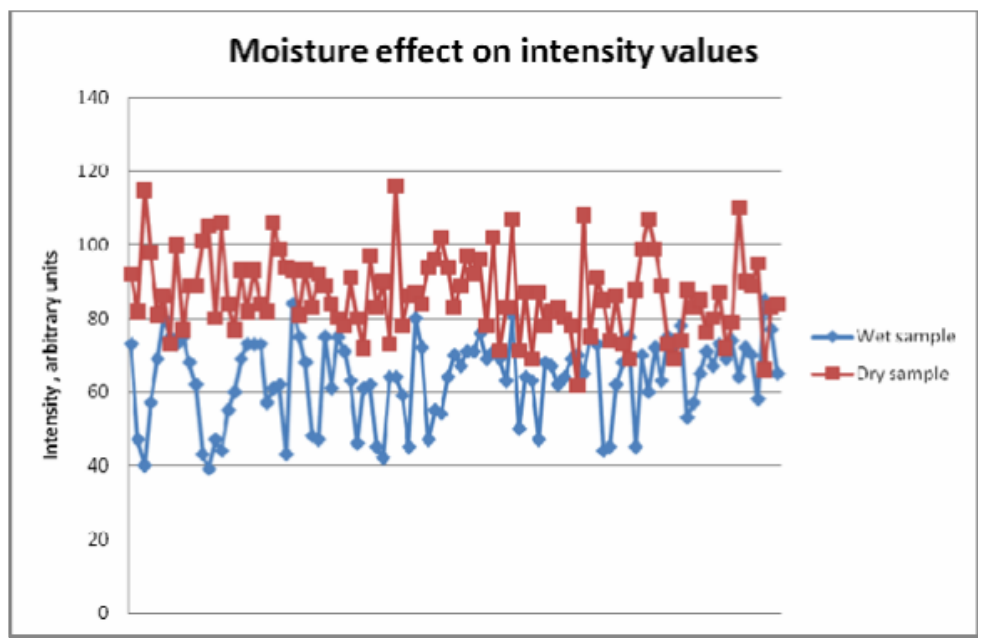

Fig. 5. The wet spot on the road during the flight campaign. Intensity values from the wet spot (blue line and dots) and the dry spot nearby (red). (Kaasalainen et al., 2010) 


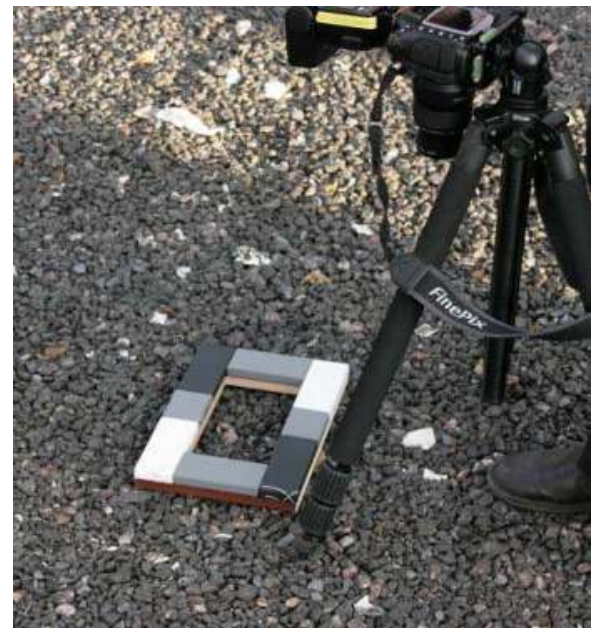

Fig. 6. Using digital camera and calibration frame to measure sample areas in Espoonlahti, Finland.

\section{Automatic gain control}

Automatic Gain Control (AGC) is one of the features that are used with the latest ALS systems. The purpose of AGC is to increase the number of received echoes and reduce oversaturation. Since the distance measurement in ALS is connected to the pulse width, the oversaturation (or ringing effect) has direct effect on range accuracy.

The ALS receiver has a lower and upper level. Any received signal that is weaker than the lower level is not recorded, and any signal that is stronger than upper level causes oversaturation which causes errors in time measurements (see Fig. 7).

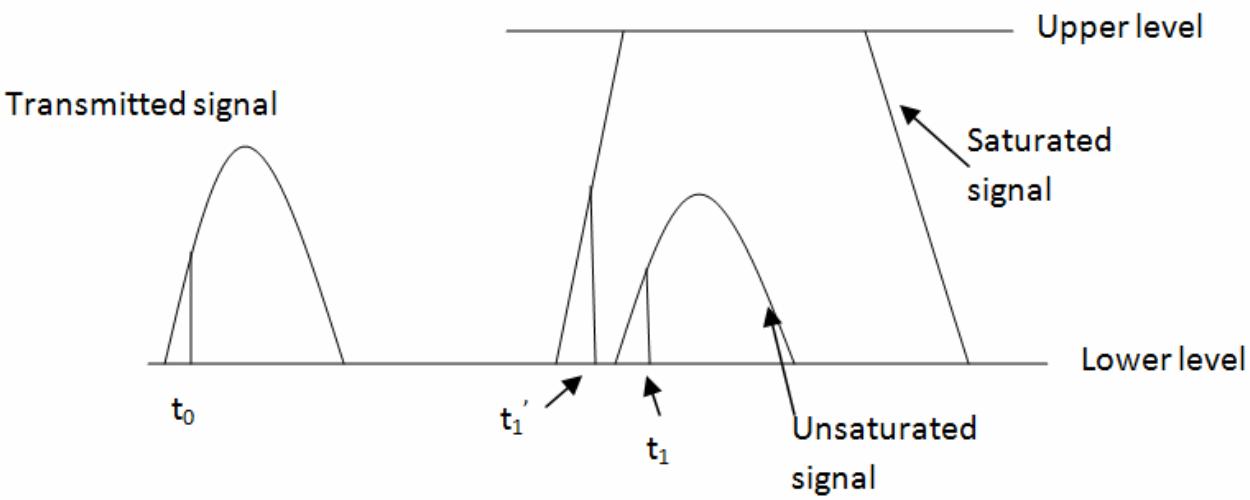

Fig. 7. The signals from very bright targets can cause received signals to oversaturate which in turn causes the error in the time measurement. The unsaturated "normal" signal does not cause error in time measurement. 
Oversaturated signal in Fig. 7 causes the time measurement error (difference between $t_{1}{ }_{1}$ and $\mathrm{t}_{1}$ ) which means that the range is not right, because the range is determined by the measurements in time difference between transmitted and received signal (Baltsavias, 1999).

The task of AGC is to keep the signal within the upper and lower levels. If there is a signal that is weaker than the lower level, the gain will increase by 1 step. Or if the signal is stronger than the upper level, then it will reduce the gain by 1 step. The AGC in Leica ALS50-II system has 256 steps and the speed of increase or decrease can be adjusted. Two switches control the increase and decrease speed. For each speed (16 speeds) level there is a certain number of points assigned. For example, if the level is set to position 10, this means that there has to be 144 consecutive laser signals that are below the lower level to increase the gain by 1 step. These levels help to control the amount of how much the gain is fluctuating. If there are a lot of water object in the area, it means that the gain will ramp up if the laser shots are coming from the water and if the laser hits the ground or trees, the gain will start to ramp down again. With the AGC working properly the gain is fluctuating constantly.

The gain and intensity is correlated quite strongly. Therefore, if the gain is fluctuating, the intensity is changing also, even though the target area might be the same (e.g., asphalt road). On Fig. 8 the AGC effect on intensity is clearly visible. The test flight was made in January 2010 in North-West Estonia. The same area was flown twice at the altitude of $500 \mathrm{~m}$. Once with AGC working properly and second time the AGC was set to a constant level (same as previous ALS systems). The AGC increases the number of returns which can be seen clearly on the water (top image have less points on the water than bottom image). And it also "messes up" the intensity image which makes the use on intensity data very difficult (e.g., in automatic classification of object based on intensity values).

The Fig. 9 shows that the intensity is changing according to the changes in AGC values. The sample data was collected in Hyytiälä, Finland 2008. The intensity, when AGC was turned on (blue line), is changing according to the changes in AGC (red line) values.

The intensity data has to be corrected for AGC effect. Vain et al., (2010) propose a correction model that is based on test flights made in Hyytiälä, Finland in 2008. Same area was flown twice: once with AGC working properly and second time when the AGC was set to a constant level. Using least square fitting a model was generated with $\mathrm{R}^{2}=0.76$. The model itself is as follows (Vain et al., 2010):

$$
I_{\text {off }}=a_{1}+a_{2} I_{\text {on }}+a_{3} I_{o n} A G C
$$

where $\mathrm{I}_{\text {off }}$ is the intensity value when the AGC is turned off or set to a constant level, $\mathrm{I}_{\text {on }}$ is observed intensity value with AGC turned on and AGC is the automatic gain control value itself. The parameters are: $a_{1}=-8.093883 ; a_{2}=2.5250588 ; a_{3}=-0.0155656$. Using equation (11) to normalise the intensity for AGC effect the relation between observed $\mathrm{I}_{\text {off(obs) }}$ (intensity values from the flight where AGC was set to constant) and calculated intensity $\mathrm{I}_{\text {off }}$ was determined. The root-mean-squared error between those two data sets was 5.65. Same model was used to correct the beach sand sample (see Fig. 10).

As we can see from Fig. 10 the model still follows the original $\left(\mathrm{I}_{\text {off }}\right)$ trend. That is the reason why AGC has to be studied further. More information about the AGC should be given by the manufacturers. There is also an other approach introduce by Korpela et al., (2010). 


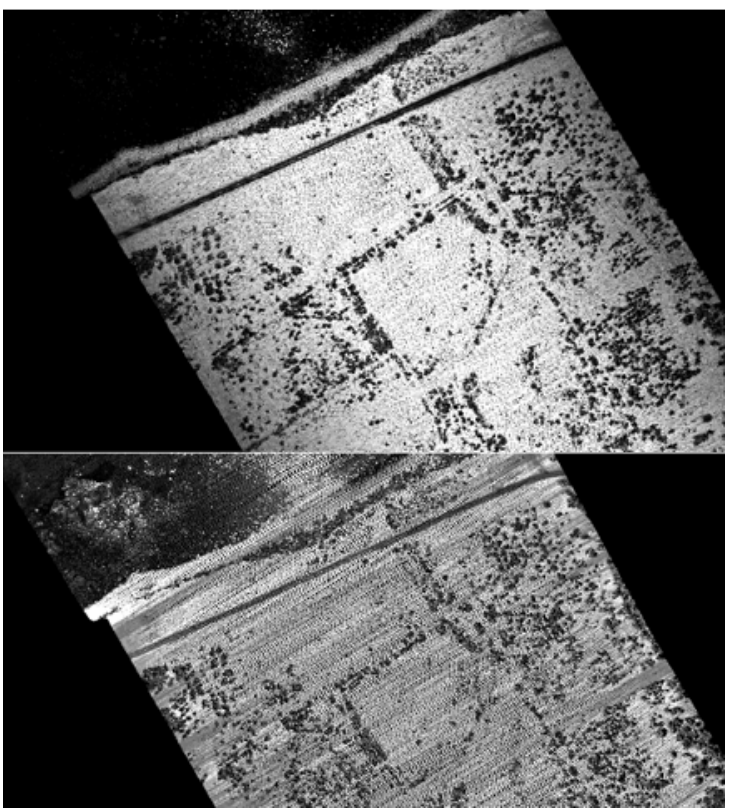

Fig. 8. Top: Test area flown with the gain set to a constant level. The intensity image is homogeneous and there are only few points on the water (top part of the picture).

Bottom: The same test area flown with gain fluctuating constantly. The intensity image is much more "messy" than with constant gain. Also there are much more point on the water.

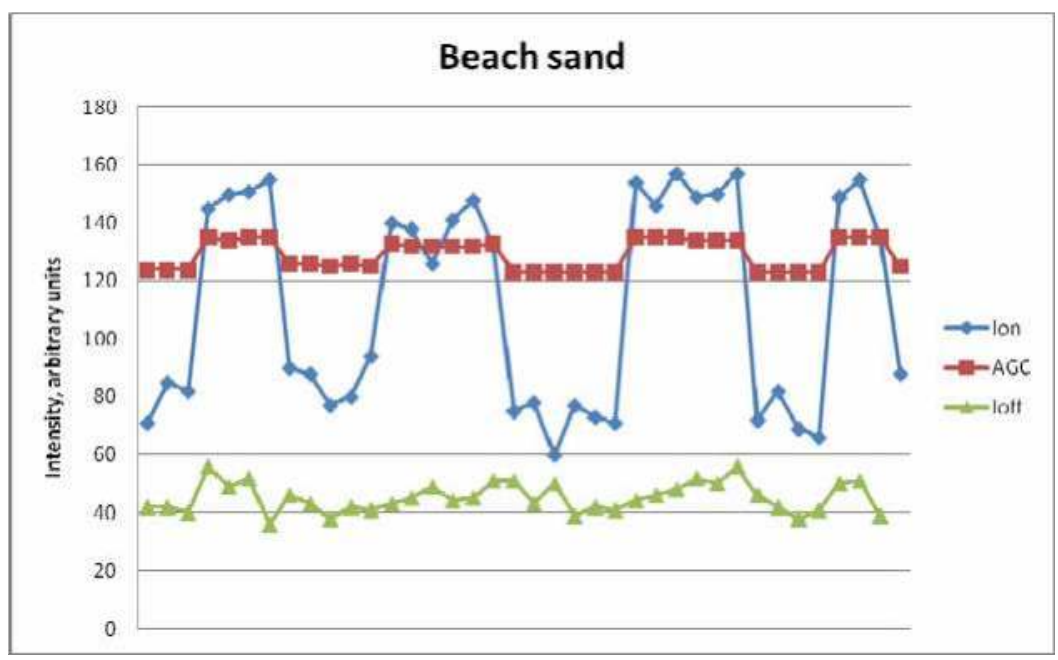

Fig. 9. AGC effect on intensity. Beach sand data collected from Hyytiälä, Finland. Blue line represent the intensity values when the AGC was turned on, red line is the AGC values itself and the green line is the intensity values when the AGC was turned off. (Vain et al., 2010) 


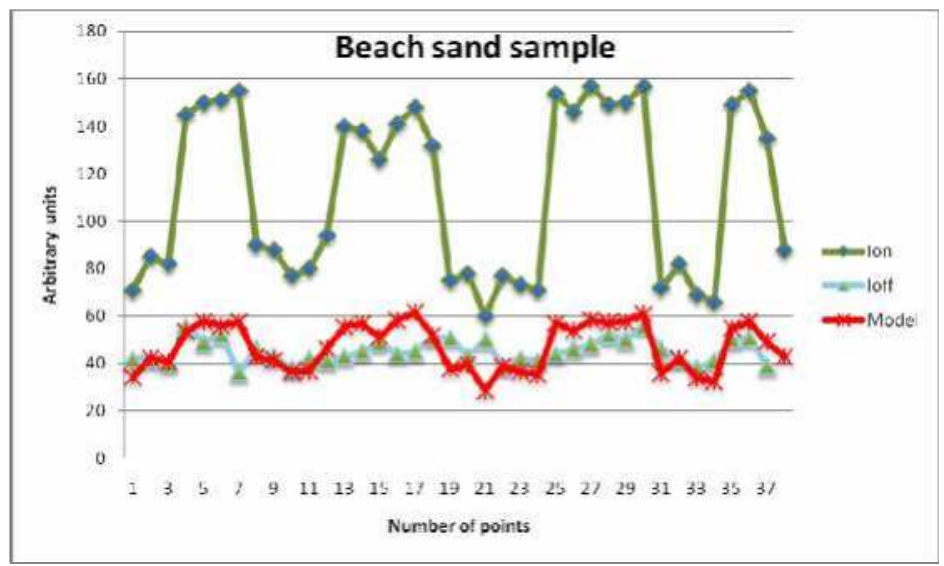

Fig. 10. Beach sand sample points corrected for AGC effect („Model“ line, red). (Vain et al., 2010)

\section{Conclusions}

The intensity data can be used in several applications and therefore has a huge potential in the future studies of the environment. The correction and calibration of ALS intensity plays a crucial part in the usage of that data. This chapter introduces the problems that occur when we manage the intensity values. The atmosphere is an important factor that affects the results, also different flight settings (PRF, flying altitude, scan angle). The targets that can be used as calibrators were introduced (tarps and asphalt).

A new feature in the ALS systems is the AGC. It makes the range measurements more accurate and increases the point density. But if we look at the side of using intensity data with AGC, then there is a problem. AGC has a clear effect on the intensity data that was shown also in this chapter. More information from the manufactures is needed, and also more tests and studies to make the correction model as good as possible.

\section{Acknowledgements}

The authors would like to thank Prof. Kalev Sepp from the Estonian University of Life Sciences for supporting this work and Harri Kaartinen from the Finnish Geodetic Institute.

\section{References}

Baltsavias, E. P. (1999). Airborne laser scanning: basic relations and formulas. ISPRS Journal of Photogrammetry E Remote Sensing, Vol. 54, pp. 199-214, ISSN 0924-2716.

Chasmer, L., Hopkinson, C., Smith, B. \& Treitz, P. (2006). Examining the influence of changing laser pulse repetition frequencies on conifer forest canopy returns. Photogrammetric Engineering \& Remote Sensing, Vol. 72, No. 12 (December 2006), pp. 1359-1367. ISSN 0099-1112.

Coren, F. \& Sterzai, P. (2006). Radiometric correction in laser. International Journal of Remote Sensing, Vol. 27, No. 15-16 (August 2006), pp. 3097-17, ISSN 0143-1161. 
Honkavaara, E., Merkelin, L., Ahokas, E., Kuittinen, R. \& Peltoniemi, J. (2008). Calibrating digital photogrammetric airborne imaging systems in a test field. The International Archives of the Photogrammetry, Remote Sensing and Spatial Information Sciences, Vol. 37/B1, pp. 555-560, ISSN 1682-1750.

Höfle, B. \& Pfeifer, N. (2007). Correction of laser scanning intensity data : Data and modeldriven approaches. ISPRS Journal of Photogrammetry \& Remote Sensing, Vol. 62, pp. 415-433, ISSN 0924-2716.

Kaasalainen, S., Ahokas, E., Hyyppä, J. \& Suomalainen, J. (2005). Study of surface brightness from backscattered laser intensity: calibration of laser data. IEEE Geoscience and Remote Sensing Letters, Vol. 2, No. 3 (July 2005), pp. 255-259. ISSN 1545-598X.

Kaasalainen, S., Kukko, A., Lindroos, T., Litkey, P., Kaartinen, H., Hyyppä, J. \& Ahokas, E. (2008). Brightness measurements and calibration with airborne and terrestrial laser scanners. IEEE Transactions on Geoscience and Remote Sensing, Vol. 46, No. 2 (February 2008), pp. 528-534. ISSN 0196-2892.

Kaasalainen, S., Niittymäki, H., Krooks, A., Koch, K., Kaartinen, H., Vain, A, and Hyyppä, H. (2010). Effect of target moisture on laser scanner intensity. IEEE Transactions on Geoscience and Remote Sensing,Vol.48, No.4, pp. 2128-2136. ISSN 0196-2892.

Kim, I. I., McArthur, B. \& Korevaar, E. (2001). Comparison of laser beam propagation at 785 $\mathrm{nm}$ and $1550 \mathrm{~nm}$ in fog and haze for optical wireless communication, In Proceeding of SPIE, 2414, pp. 26-37, Boston, November, 2000.

Korpela, I., Ørka, H. O., Hyyppä, J., Heikkinen, V. \& Tokola, T. (2010). Range and AGC normalization in airborne discrete-return LiDAR intensity data for forest canopies. ISPRS Journal of Photogrammetry and Remote Sensing, Vol. 65, pp. 369-379. ISSN 09242716.

Kukko, A., Kaasalainen, S. \& Litkey, P. (2008). Effect of incidence angle on laser scanner intensity and surface data. Applied Optics, Vol. 47, No. 7 (March 2008), pp. 986-992, ISSN 1559-128X.

Vain, A., Kaasalaine, S., Pyysalo, U., Krooks, A. \& Litkey, P. (2009). Use of naturally available reference targets to calibrate airborne laser scanning intensity data. Sensors, Vol. 9, pp. 2780-2796 (April 2009), ISSN 1424-8220.

Vain, A., Yu, X., Kaasalainen, S. \& Hyyppä, J. (2010). Correcting airborne laser scanning intensity data for automatic gain control effect. IEEE Geoscience and Remote Sensing Letters, Vol. 7, No. 3 (July 2010), pp. 511-514. ISSN 1545-598X.

Wagner, W. (2010). Radiometric calibration of small-footprint full-waveform airborne laser scanner measurements: Basic physical concept. ISPRS Journal of Photogrammetry and Remote Sensing, In Press. 


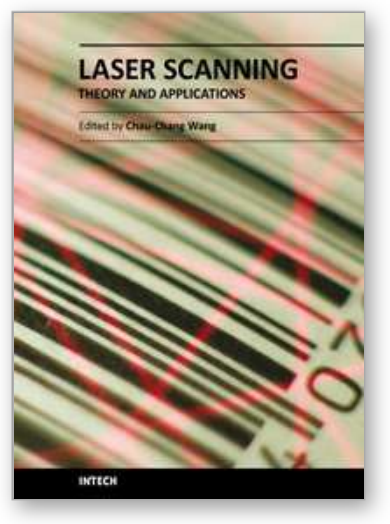

\author{
Laser Scanning, Theory and Applications \\ Edited by Prof. Chau-Chang Wang
}

ISBN 978-953-307-205-0

Hard cover, 566 pages

Publisher InTech

Published online 26, April, 2011

Published in print edition April, 2011

Ever since the invention of laser by Schawlow and Townes in 1958, various innovative ideas of laser-based applications emerge very year. At the same time, scientists and engineers keep on improving laser's power density, size, and cost which patch up the gap between theories and implementations. More importantly, our everyday life is changed and influenced by lasers even though we may not be fully aware of its existence. For example, it is there in cross-continent phone calls, price tag scanning in supermarkets, pointers in the classrooms, printers in the offices, accurate metal cutting in machine shops, etc. In this volume, we focus the recent developments related to laser scanning, a very powerful technique used in features detection and measurement. We invited researchers who do fundamental works in laser scanning theories or apply the principles of laser scanning to tackle problems encountered in medicine, geodesic survey, biology and archaeology. Twenty-eight chapters contributed by authors around the world to constitute this comprehensive book.

\title{
How to reference
}

In order to correctly reference this scholarly work, feel free to copy and paste the following:

Ants Vain and Sanna Kaasalainen (2011). Correcting Airborne Laser Scanning Intensity Data, Laser Scanning, Theory and Applications, Prof. Chau-Chang Wang (Ed.), ISBN: 978-953-307-205-0, InTech, Available from: http://www.intechopen.com/books/laser-scanning-theory-and-applications/correcting-airborne-laser-scanningintensity-data

\section{INTECH}

open science | open minds

\section{InTech Europe}

University Campus STeP Ri

Slavka Krautzeka 83/A

51000 Rijeka, Croatia

Phone: +385 (51) 770447

Fax: +385 (51) 686166

www.intechopen.com

\section{InTech China}

Unit 405, Office Block, Hotel Equatorial Shanghai

No.65, Yan An Road (West), Shanghai, 200040, China

中国上海市延安西路 65 号上海国际贵都大饭店办公楼 405 单元

Phone: +86-21-62489820

Fax: $+86-21-62489821$ 
(C) 2011 The Author(s). Licensee IntechOpen. This chapter is distributed under the terms of the Creative Commons Attribution-NonCommercialShareAlike-3.0 License, which permits use, distribution and reproduction for non-commercial purposes, provided the original is properly cited and derivative works building on this content are distributed under the same license. 